\title{
Demystifying the Sundarban tiger: novel application of conventional population estimation methods in a unique ecosystem
}

\author{
Manjari Roy $^{1}$ - Qamar Qureshi ${ }^{1} \cdot$ Dipanjan Naha $^{1} \cdot$ Kalyanasundaram Sankar $^{1}$ • \\ Rajesh Gopal $^{2,3} \cdot$ Yadvendradev Vikramsinh Jhala ${ }^{1}$
}

Received: 25 February 2015/ Accepted: 5 November 2015/Published online: 15 December 2015

(c) The Author(s) 2015. This article is published with open access at Springerlink.com

\begin{abstract}
Conserving large populations with unique adaptations is essential for minimizing extinction risks. Sundarban mangroves $\left(>10,000 \mathrm{~km}^{2}\right)$ are the only mangrove inhabited by tigers. Baseline information about this tiger population is lacking due to its man-eating reputation and logistic difficulties of sampling. Herein, we adapt photographic capture-mark-recapture (CMR) and distance sampling to estimate tiger and prey densities. We placed baited camera stations in a typical mangrove in 2010 and 2012. We used telemetry based tiger home-range radius $(5.73 \mathrm{~km}, \mathrm{SE} 0.72 \mathrm{~km})$ to estimate effective trapping area (ETA). An effort of 407 and 1073 trap nights were exerted to photocapture 10 and 22 unique tigers in 2010 and 2012. We accounted for use of bait by modelling behaviour and heterogeneity effects in program MARK and secr package in program $\mathrm{R}$. Using traditional CMR, tiger number was estimated at 11 (SE 2) and density at 4.07 (SE range 3.09-5.17) in 2010 while in 2012, tiger number was 24 (SE 3) and density 4.63 (SE range $3.92-5.40$ ) tigers $/ 100 \mathrm{~km}^{2}$. With likelihood based spatially explicit CMR, tiger densities were estimated at 4.08 (SE 1.51) in 2010 and 5.81 (SE 1.24) tigers $/ 100 \mathrm{~km}^{2}$ in 2012 . Using distance sampling along water channels, we estimated chital density at 5.24/ $\mathrm{km}^{2}$, SE 1.23 which could potentially support 4.68 tigers/ $100 \mathrm{~km}^{2}[95 \% \mathrm{CI}(3.92,5.57)]$. Our estimates suggest that
\end{abstract}

Yadvendradev Vikramsinh Jhala

jhalay@wii.gov.in

1 Wildlife Institute of India, Chandrabani, Dehradun 248001, India

2 National Tiger Conservation Authority, Ministry of Environment, Forests and Climate Change, New Delhi, India

3 Global Tiger Forum, Jorbaug Road, New Delhi, India
Sundarban tiger population is one of the largest in the world and therefore merits high conservation status.

Keywords Baited traps - Capture-mark-recapture . Carnivore carrying capacity $\cdot$ Mangrove $\cdot$ Prey density . Spatially explicit tiger density

\section{Introduction}

Anthropogenic pressures are increasingly fragmenting and disconnecting tiger occupied forest patches all over Asia. The future persistence of this species depends upon conservation measures rooted in protecting "representative, redundant, and resilient" populations across the historical range over which it has evolved (Sanderson et al. 2006). Since such diverse habitats are likely to produce dissimilar ecological adaptations and dynamics, it is not justified to focus only on large tiger populations (Dinerstein et al. 1997). One such habitat, the mangroves, is exclusively represented by Sundarban that supports one of the largest tiger populations across India and Bangladesh (Jhala et al. 2011). Sundarban tigers differ in morphology from that of their geographically closest conspecifics $(P$. tigris tigris, Linnaeus and P. tigris corbetti, Mazak) (Barlow 2009) and represent, at the least, an Evolutionary Significant Unit (Singh et al. 2015). The ambit of conserving Sundarban extends beyond its charismatic species. Sundarban has the distinction of being the largest $\left(10,263 \mathrm{~km}^{2}\right)$ and most diverse mangrove forest in the world, spanning across India and Bangladesh (Chaudhuri and Choudhury 1994). These mangroves play a critical role in coastal ecology by buffering inlands from cyclones, stabilising sediments and aiding land maturation (Blasco et al. 1996). This tiger habitat is also in close proximity to one of the densest 
(1437.4 persons $/ \mathrm{km}^{2}$, Qureshi et al. 2006) and poorest (Kanjilal et al. 2010) human populations, where many local communities derive substantial portion of their livelihood from harvesting forest products like fish, giant tiger shrimp (Penaeus monodon, Fabricius) and honey (Blair 1990; Rahman 2000; Islam and Wahab 2005). Interestingly, the fate of Sundarban tiger is intertwined with local livelihoods, and mangrove conservation. However, Sundarban faces a precarious future primarily due to a rising sea level, coastal squeeze (Loucks et al. 2010) and water pollution. In Sundarban, human-tiger conflicts involving attack and killing by the tiger are more recurrent than in any other tiger area of the world (Neumann-Denzau and Denzau 2010). Chakrabarti (1992) estimated that about 36 people were killed each year in the Indian Sundarban. In Bangladesh Sundarban, Barlow et al. (2013) estimated a mean of 22 human deaths per year. Ironically, the infamous "man-eating" tiger has been the archetypal symbol of this mangrove forest and it is this fear that is partly responsible for the continual survival of Sundarban forests by minimising overexploitation of forest resources.

Survival of threatened taxa in today's world largely depends on research informed management actions, augmented with systematic monitoring of their population status (Yoccoz et al. 2001). However, rigorous scientific research on Sundarban tigers is scarce due to the logistic constraints imposed by a difficult to work environment coupled with the ever present threat of being killed by tigers. This has led to a paucity of information on their basic ecology and population parameters. Past efforts of estimating tiger abundance in this region have reported densities ranging from as high as $23.5 / 100 \mathrm{~km}^{2}$ (Barlow 2009) to as low as $0.7 / 100 \mathrm{~km}^{2}$ (SD 1.67) (Karanth and Nichols 2000) while the reserve management (West Bengal Forest Department) claimed 250 tigers (a density of 20/100 $\mathrm{km}^{2}$ ) (Mukherjee 2005). These discrepancies can be attributed to less reliable exercises based on untested assumptions, and have in turn impeded the assessment of management efficacy towards conserving this population.

In this paper we used standard capture-mark-recapture with camera traps to obtain reliable estimates of tiger abundance in the Sundarban. Information from radio-collared tigers was used to delineate the study area so as to achieve geographic closure and obtain a more reliable estimate of effective trapping area. We conducted a pilot study in an area of about $270 \mathrm{~km}^{2}$ in Sundarban Tiger Reserve in 2010 to assess the feasibility of camera trapping. After successful implementation of this exercise, the camera trapped area was enlarged in 2012 to about $518 \mathrm{~km}^{2}$. We also estimated prey densities using boat transects by distance sampling to investigate if our estimated tiger abundance could be supported by the available prey base (Hayward et al. 2007). This study used rigorous scientific techniques to provide a reliable estimate of tiger and prey abundance for a unique mangrove habitat, which is the first step towards understanding their ecology and developing effective conservation strategies.

\section{Methodology}

\section{Study area}

Indian Sundarban $\left(21^{\circ} 31^{\prime}-22^{\circ} 30^{\prime} \mathrm{N}\right.$ and $\left.88^{\circ} 10^{\prime}-89^{\circ} 51^{\prime} \mathrm{E}\right)$ comprises $41 \%$ of the entire Sundarban landscape (Chaudhuri and Choudhury 1994). In recognition of its ecological and cultural significance, it has been brought under legal framework as a tiger reserve which encompasses a wildlife sanctuary, a national park and its buffer zone. Sundarban is also recognized as a World Heritage Site and a biosphere reserve. Sundarban is the most ecologically important tidal forest in India with around 35 mangrove species and 117 other halophytic mangrove associates (Qureshi et al. 2006). Prey species of tigers in the region are chital (Axis axis, Erxleben) and wild pig (Sus scrofa, Linnaeus) (Khan 2004) and also purportedly include Rhesus macaque (Macaca mulatta, Zimmermann), lesser adjutant stork (Leptoptilos javanicus, Horsfield), water monitor lizard (Varanus salvator, Laurenti), crabs and fishes (De 1990). The landscape is criss-crossed by varying widths of water channels and is subjected to daily tidal fluctuations. The tidal range also changes with the lunar cycle. At spring tides, during the time of full and new moon, the tidal range and water speed reach a maximum, covering a major portion of the landmass with tidal water for a few hours. During neap tides, occurring at the first and third quarter moon phases, tidal range is significantly reduced and water speed is weaker (Kvale 2006). We conducted this study during 2010-2012 in the West Range of the Sundarban Tiger Reserve which is a core tiger conservation area and a typical mangrove habitat.

\section{Estimating tiger abundance}

\section{Field methods}

We used camera trap based photographic capture-recapture analysis to estimate tiger abundance (Karanth and Nichols 1998). We had previously tagged four individuals (one female and three males) with GPS PLUS Iridium satellite collars (VECTRONIC Aerospace GMbH, Berlin, Germany). We found that tigers rarely crossed channels greater than $1 \mathrm{~km}$ width (Y. V. Jhala et al., unpublished data). Therefore, we chose a study area for camera trap population estimation that was bound on almost all sides by $>1 \mathrm{~km}$ wide channels to ensure short-term geographic 
population closure and minimise the uncertainty associated with our effective sampling area. Although camera traps are usually deployed on tiger frequented trails to optimize detection probability, it was infeasible to conduct extensive foot surveys due to the omnipresent threat from tigers and lack of trails due to tidal effects. Hence, we located trapping stations by boats in accessible areas with ample visibility to minimize chances of lethal encounters with tigers. We lured tigers to our camera stations with food (meat-2 to $5 \mathrm{~kg}$ ) (Fig. 1a) and fresh water as bait (Fig. 1b) to maximise photo-capture rates (Gerber et al. 2012; du Preez et al. 2014). We also oriented tigers to approach baits using nets and cut vegetation so as to obtain both flank pictures for individual identification (Fig. 1a). We used passive infra-red Moultrie Game Spy D-40 Digital Game cameras (Moultrie Feeders, Alabama, USA). We set up 11 camera trap stations during October 24-December 17 in 2010 in about $270 \mathrm{~km}^{2}$ area and 30 stations during February 12April 6 in 2012 in a larger area of about $518 \mathrm{~km}^{2}$. The
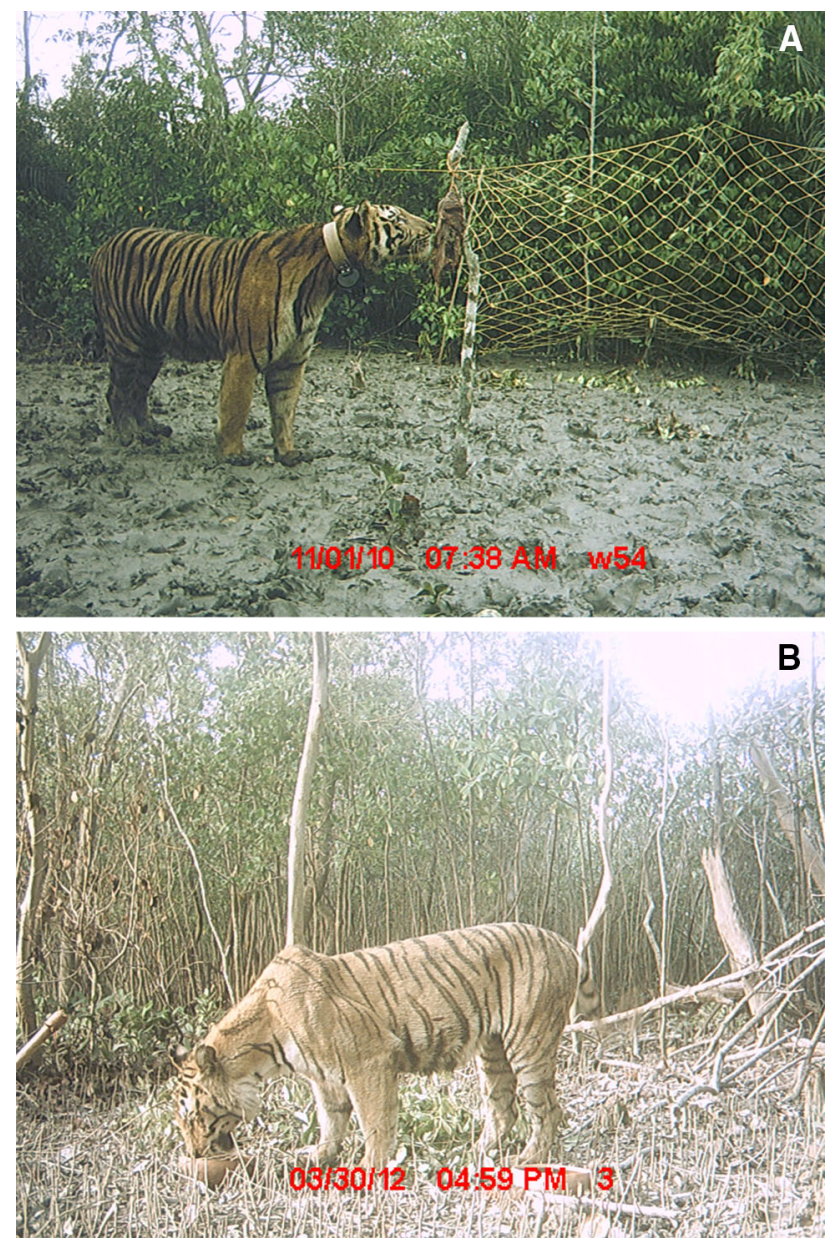

Fig. 1 a A radio-collared tiger photocaptured on a baited station in the Sundarban Tiger Reserve. b. A photocaptured tiger drinking fresh water at a baited camera trap station in the Sundarban Tiger Reserve. Note the net and cut vegetation in the background used to orient the approach of the tiger to the baited station distance between adjacent camera stations were maintained at 2-4 km to ensure no large "holes" were left in the study area (Karanth and Nichols 1998). Trapping stations comprised of two cameras, at $40-45 \mathrm{~cm}$ height from the ground, facing each other across a maximum distance of $8 \mathrm{~m}$ to capture both flanks of the animal. To minimize damage to cameras due to submergence during spring high tide when water levels rose by a few meters, we deployed them for 9-10 neap tide days when the high tide water levels were low, and removed them for the next 4-5 spring tide days when water levels reached maximum height, continuing this cycle for a maximum of 55 days in both years to maintain demographic closure. We inspected stations after every 2 days for ensuring proper functioning of cameras and replenishing the baits to minimize spatiotemporal heterogeneity in tiger visitation among stations (Gerber et al. 2012).

\section{Analytical methods}

We used photographs of tigers more than 1 year of age for analysis as younger animals rarely accompany mothers on foraging trips and are underrepresented in camera trap studies (Karanth and Nichols 1998). They are also the most vulnerable cohort to mortality events in the short term. We identified individual tigers by their stripe patterns and their detection history across sampling occasions was summarized into a standard " $X$ matrix" (Otis et al. 1978). We defined each discrete sampling occasion as a $24-\mathrm{h}$ period starting at $0000 \mathrm{~h}$. We estimated population abundance within the trapped area $(\hat{N})$ in the conventional way using program MARK v 6.2 (White and Burnham 1999). We formulated capture-recapture models that assumed (a) constant detectability $\left(M_{\mathrm{o}}\right)$, (b) behavioural response of tigers to camera trapping $\left(M_{\mathrm{b}}\right)$, (c) heterogeneity of detectability between individuals $\left(M_{\mathrm{h}}\right)$, or (d) combined effect of heterogeneity and behavioral response on detection $\left(M_{\mathrm{bh}}\right)$. Due to small number of photo-captured tigers, and since we used the same methods in 2010 and 2012, the detection probability of tigers would likely be the same between the years. By borrowing information on detection probability (Lebreton et al. 1992; Williams et al. 2002) from both years, we would have a more robust estimate. While building models, we therefore allowed detection probability parameters to vary or remain constant between years. We selected the model with minimal Akaike Information Criteria corrected for sample size $\left(\mathrm{AIC}_{\mathrm{c}}\right.$, Akaike 1974) for inference. To accommodate model uncertainty we used multi-model inference, wherein we use AIC weighted average estimates from models differing by $2 \Delta$ AIC units (Burnham and Anderson 2002). For estimating the spatial coverage of the trappable population, we added a buffer of 5.73 (SE 0.72) 
$\mathrm{km}$ (the average home range radius obtained from $95 \%$ fixed kernel areas of four radiocollared tigers) around the minimum bounding polygon joining the outermost camera traps (Jhala et al. 2011). Channels wider than $1 \mathrm{~km}$ width were masked out in the effective trapping area $(\widehat{E T A})$ calculation. The estimate of variability on $\widehat{E T A}$ was obtained by buffering the minimal bounding polygon with a buffer of one standard error on home-range radius and subsequent removal of non-tiger habitat from the computation in ArcGIS 9.3 (ESRI 2011). The conventional population density $(\hat{D})$ was then estimated as $\hat{N} / \widehat{E T A}$. The variability in tiger density (Karanth and Nichols 1998) is typically computed by combining the variability in population estimates with the variability in $\widehat{E T A}$ by using the delta method (Seber 1973). However, this approach assumes a uniform buffer around the $\widehat{E T A}$ and does not account for the associated patchiness in tiger habitat and non-habitat. Therefore, we computed the potential variation in tiger density in a geographical information system (GIS), wherein, the lower limit of tiger population was divided by the upper estimate of effective area (obtained from the GIS analysis) to estimate the lower limit of tiger density while the higher limit of tiger population was divided by the lower effective area to estimate the upper tiger density limit.

Spatially explicit capture-recapture models (SECR; Efford 2004; Borchers and Efford 2008) estimate density directly from the spatial capture histories thereby avoiding the use of ad hoc estimation of ETA done in traditional capture-recapture studies. SECR uses spatial histories of individual animals to construct centre of activity from where its detection declines as we move away. This process is modelled by two parameters-(1) g0, the detection probability at the activity centre and (2) sigma, the spatial movement parameter. We implemented SECR analysis in the maximum likelihood framework using the secr package (Efford 2015) in program $\mathrm{R} v$ 3.1.3 (R Core Team 2015). We created two matrices that summarized the spatio-temporal detection history of individuals and the spatio-temporal layout of the traps. We used proximity detectors specifying a buffer of $18 \mathrm{~km}$. We used a habitat mask wherein, we removed areas outside the temporary hard boundaries demarcated by water channels $>1 \mathrm{~km}$ width (Fig. 2). Similar to the abundance estimation, we estimated tiger density of the 2 years separately, while borrowing the information on $\mathrm{g} 0$ and sigma from both years. We modelled $\mathrm{g} 0$ as constant (null), influenced by behaviour ( $\mathrm{b}$, where capture and recapture probabilities for tigers differ), and with trap-specific behaviour (bk, where the capture and recapture at specific traps differ) and sigma as constant (null) or with two group heterogeneity ( $h 2$, differing in their movement patterns as two groups). The decline in detection as we move away from the activity centre was modelled using a half- normal distribution function. We then selected the model with minimal Akaike Information Criterion (Akaike 1974) as the best model.

\section{Prey density and carrying capacity}

To estimate prey density, we conducted distance sampling along river channels based on boat transects cruising at $5 \mathrm{~km} / \mathrm{h}$ in 2011, 2012 and 2013. During boat surveys, we recorded the perpendicular distance of animal groups and the channel bank edge from the observer (in order to remove the non-habitat water) with range finder Scout DX 1000 Arc (Bushnell, Missouri, USA), and the animal group size. Data on perpendicular distances of observations from the water edge to the animal, pooled across years, was used to estimate density in program DISTANCE v 6.0 (Thomas et al. 2009). We truncated observations $>75 \mathrm{~m}$ after detecting signs of peaking, and fitted half-normal and hazard rate functions with cosine and polynomial adjustments. We selected the model with minimum Akaike Information Criterion (Akaike 1974) to estimate the global detection probability, thereafter obtaining annual densities by poststratification (see Thomas et al. 2010). We used the equation developed by Hayward et al. (2007) for lions to estimate the carrying capacity of Sundarban for tigers since tigers and lions have similar food requirements and both are apex predators. The prey population biomass was estimated as three-fourth of the average female weight of the prey species multiplied by the average prey density (Hayward et al. 2007). We used only chital density to compute the carrying capacity since wild pig, rhesus macaque and lesser adjutant stork constituted less than $5 \%$ of the prey biomass. We used the lower and upper confidence limits on chital density to compute the lower and upper limits of the potential carrying capacity of the study area.

\section{Results}

\section{Tiger abundance}

Our sampling efforts comprised of 37 occasions (in both years) with an effort of 407 trap nights in 2010 and 1073 trap nights in 2012. Number of unique tigers captured $\left(M_{t+1}\right)$ was 10 in 2010 and 22 in 2012. The models in increasing order of AIC were-

$$
\begin{aligned}
& M_{\mathrm{bh}}(\mathrm{AIC} 772.80) \sim M_{\mathrm{h}}(\mathrm{AIC} 773.79)<M_{\mathrm{b}}(\mathrm{AIC} 807.04) \\
& \quad<M_{\mathrm{o}}(\mathrm{AIC} 820.05)
\end{aligned}
$$

The combined effects of individual heterogeneity and behavioural response to traps $\left(M_{\mathrm{bh}}\right)$ model was the best model and the next best model ( $\triangle$ AIC 0.98$)$ was the model 


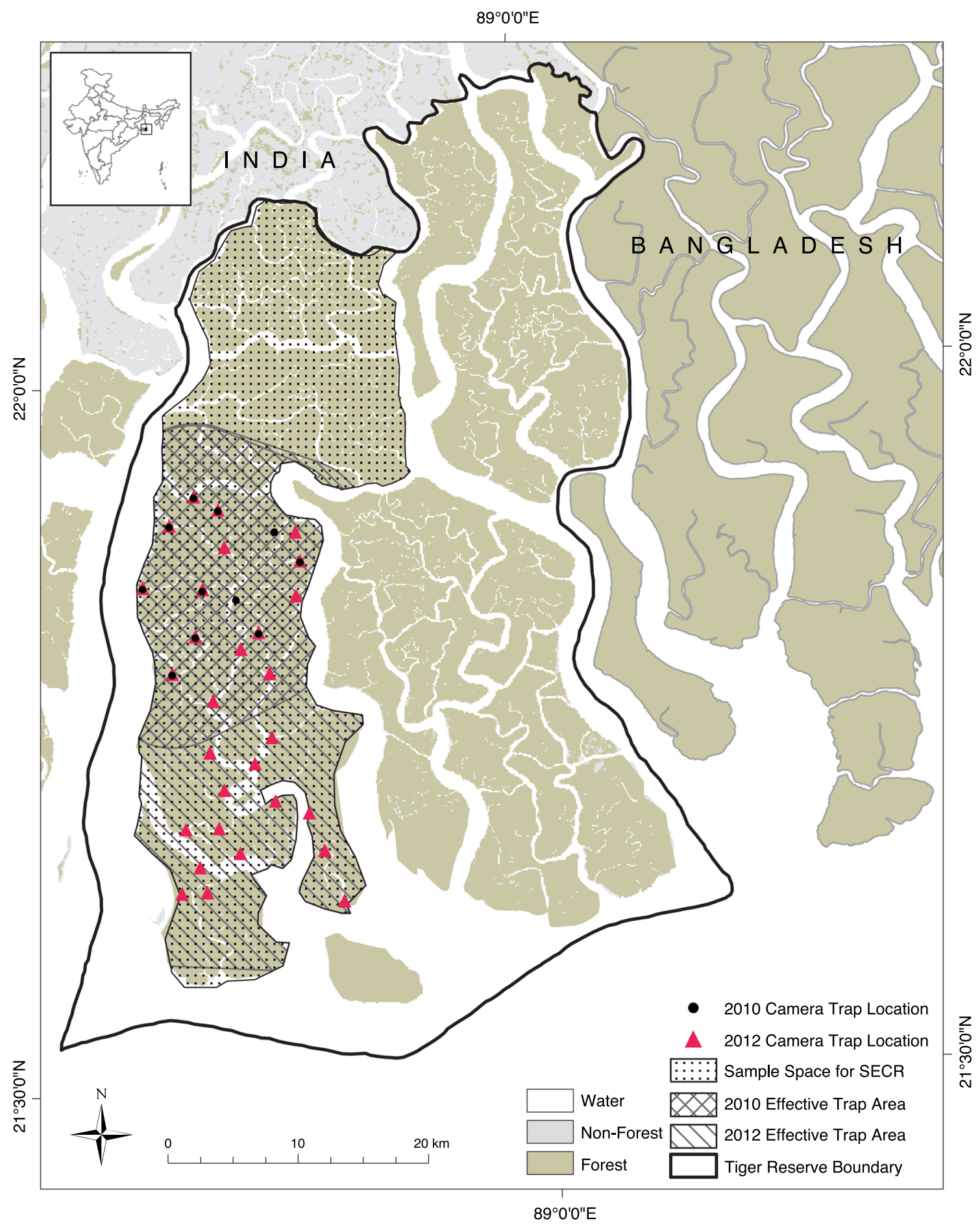

Fig. 2 Camera trap station locations, model inference space for spatially explicit capture-mark-recapture and effective trapping area for estimating tiger density in the Sundarban Tiger Reserve during 2010 and 2012. The inset map shows the location of the tiger reserve in India

incorporating individual heterogeneity $\left(M_{\mathrm{h}}\right)$ keeping the detection parameters constant across the years. Model averaged estimate of abundance $(\hat{N})$ from the two most likely models were 11 (SE 2) in 2010 and 24 (SE 3) in 2012 (Table 1).
The $\widehat{E T A}$ was estimated at 270 (SE range $251-291) \mathrm{km}^{2}$ for 2010 and 518 (SE range 500-535) $\mathrm{km}^{2}$ (Fig. 2) for 2012 that gave density estimates of 4.07 (SE range $3.09-5.17$ ) and 4.63 (SE range 3.92-5.40) tigers $/ 100 \mathrm{~km}^{2}$ for the 2 years respectively. 
Table 1 Abundance estimates of tigers from capture-mark-recapture analysis in MARK in Sundarban mangrove forests. Model averaged parameter estimates from best models $\left(M_{\mathrm{bh}}\right.$ and $\left.M_{\mathrm{h}}\right)$

\begin{tabular}{lll}
\hline Parameter & 2010 & 2012 \\
\hline$M_{t+1}$ & 10 & 22 \\
Recaptured individuals & 6 & 18 \\
Total number of camera stations & 11 & 29 \\
Traps where tigers were captured & 9 & 29 \\
Population estimate $\hat{N}$ & 11 (SE 2) & 24 (SE 3) \\
Group probability $\left(p_{i}\right)$ & 0.38 (SE 0.11) \\
Capture probability of group 1 $\left(p_{1}\right)$ & 0.05 (SE 0.02) \\
Capture probability of group 2 $\left(p_{2}\right)$ & 0.05 (SE 0.02) \\
Recapture probability of group $1\left(c_{1}\right)$ & 0.26 (SE 0.03) \\
Recapture probability of group 2 $\left(c_{1}\right)$ & 0.06 (SE 0.02)
\end{tabular}

Parameter estimates are averaged for models $M_{\mathrm{bh}}$ and $M_{\mathrm{h}}$ with AIC model weights $M_{\mathrm{bh}}$ at 0.654 , and $M_{\mathrm{h}}$ as 0.346 for the pooled tiger captures of 2010 and 2012

In SECR, the model with g0 having trap-specific behavioural response and sigma best explained as a 2-mixture heterogeneity was selected as the best model (Table 2). Tiger densities estimated by these models were 4.08 (SE 1.51 ) in 2010 and 5.81 (SE 1.24) tigers $/ 100 \mathrm{~km}^{2}$ in 2012.

\section{Prey density and carrying capacity}

The total survey effort for distance sampling was $851 \mathrm{~km}$ over 3 years with maximum number of sightings obtained for chital (Table 3).
For chital density, the hazard model with cosine adjustment was the best fit model. The global density taken over the three years was 5.24 (SE 1.23) chital $/ \mathrm{km}^{2}$. After poststratification by years, chital densities were estimated at $3.88(\mathrm{SE} 2.11) / \mathrm{km}^{2}$ in 2011, $6.88(\mathrm{SE} 1.88) / \mathrm{km}^{2}$ in 2012 and $4.94\left(\mathrm{SE} \mathrm{1.32)} / \mathrm{km}^{2}\right.$ in 2013 (Table 4).

Based on chital biomass the carrying capacity was estimated at 4.68 tigers $/ 100 \mathrm{~km}^{2}$ [95\% CI $\left.(3.92,5.57)\right]$.

\section{Discussion}

This study generated the first-ever reliable estimate of tiger abundance for the obscure yet ecologically significant Sundarban that will serve as a benchmark for developing conservation targets and plans. Tiger numbers in Sundarban had been traditionally derived using the "pugmark census" technique (Choudhury 1970, 1972), wherein plaster casts of the left hind paw were acquired on creek banks and compared to identify individuals based on perceived differences in pugmark shape and size metrics, yielding estimates of 296 tigers in 1989 (Chakrabarti 1992) for the Indian Sundarban. Karanth et al. (2003) critically reviewed the shortcomings of this technique, and pointed out that poor quality of pugmark tracings, differences between personnel skills and the biologically unrealistic assumption that all tigers can be detected, have led to inaccurate estimates of tiger numbers. In Sundarban, this technique has additionally led to high probability of misidentifying the same tiger as different individuals due to

Table 2 Density estimates of tigers from Non-spatial traditional capture-mark-recapture using home-range radius for computing ETA and Spatially explicit capture-recapture models, in Sundarban mangrove forests

\begin{tabular}{|c|c|c|c|c|c|c|c|}
\hline \multirow[t]{2}{*}{ Year } & \multicolumn{3}{|c|}{ Non-spatial estimates } & \multicolumn{4}{|c|}{ Spatially explicit estimates } \\
\hline & $\begin{array}{l}\text { Minimum } \\
\text { bounding } \\
\text { polygon } \\
\left(\mathrm{km}^{2}\right)\end{array}$ & $\begin{array}{l}\text { Effective } \\
\text { trapping area } \\
\left(\mathrm{km}^{2}\right)\end{array}$ & $\begin{array}{l}\text { Density [tigers/ } \\
100 \mathrm{~km}^{2} \text { (SE)] }\end{array}$ & Best model & $\begin{array}{l}\text { Sigma }(\sigma) \text { in } \mathrm{km}(\mathrm{SE}) \\
\text { and group } 1 \\
\text { probability } \\
\left(p_{1}\right)(\mathrm{SE})\end{array}$ & g0 (SE) & $\begin{array}{l}\text { Density } \\
\text { [tigers/ } \\
100 \mathrm{~km}^{2} \\
(\mathrm{SE})]\end{array}$ \\
\hline 2010 & 104 & $\begin{array}{l}270 \text { (SE range } \\
251-291)\end{array}$ & $\begin{array}{c}4.07(\mathrm{SE} \text { range } \\
3.09-5.17)^{\mathrm{a}}\end{array}$ & \multirow[t]{2}{*}{$\begin{array}{l}\mathrm{D} \text { (year), g0 (bk), } \sigma \\
\quad(\mathrm{h} 2)\end{array}$} & \multirow{2}{*}{$\begin{array}{l}\sigma_{1}=2.56(0.26) ; \\
\sigma_{2}=6.74(1.20) ; \\
p_{1}=0.91(0.06)\end{array}$} & \multirow[t]{2}{*}{$\begin{array}{l}0.026 \\
(0.01)\end{array}$} & $4.08(1.51)$ \\
\hline 2012 & 372 & $\begin{array}{c}518 \text { (SE range } \\
500-535)\end{array}$ & $\begin{array}{c}4.63(\mathrm{SE} \text { range } \\
3.92-5.40)^{\mathrm{a}}\end{array}$ & & & & $5.81(1.24)$ \\
\hline
\end{tabular}

a See Table 1 for model details

Table 3 Survey effort and number of groups sighted for different species in the Sundarban mangroves for estimating density by program DISTANCE

\begin{tabular}{lccccc}
\hline Year & Total effort $(\mathrm{km})$ & \multicolumn{4}{l}{ Number of individual groups sighted } \\
\cline { 3 - 6 } & & Chital & Wild pig & Rhesus macaque & Lesser adjutant stork \\
\hline 2011 & 64 & 4 & - & 1 & 2 \\
2012 & 327 & 34 & 1 & 6 & 8 \\
2013 & 460 & 37 & 1 & 8 & 3 \\
Total & 851 & 75 & 2 & 15 & 13 \\
\hline
\end{tabular}




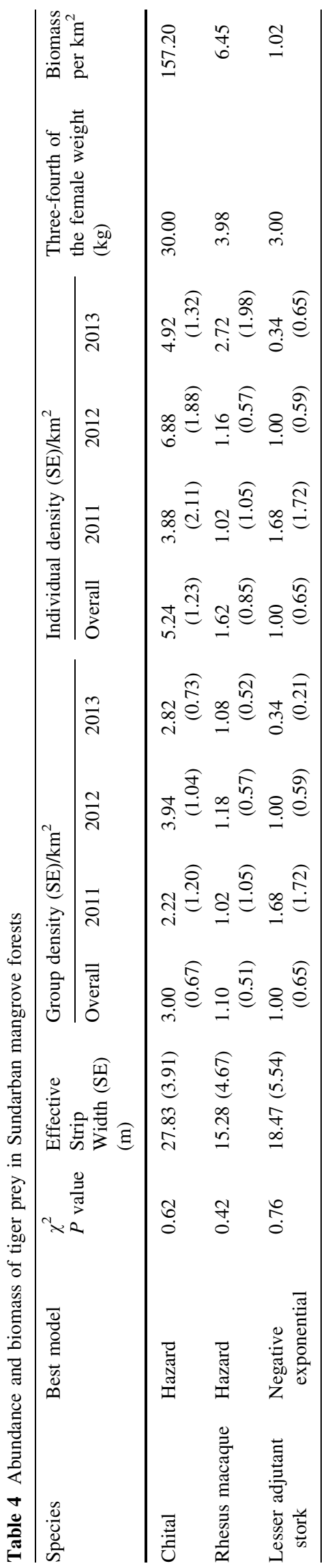

distortion/degradation of pugmarks caused by muddy conditions of substrate and constant tidal action on creek banks. Later, Karanth and Nichols (2000) carried out camera trapping based capture-recapture in a subset of this landscape, reporting average tiger density of 0.7 tigers/ $100 \mathrm{~km}^{2}$ (SD 1.67). The major shortcoming of this study arose from large and varying distances between neighboring camera traps, creating sampling holes, wherein residing individuals would be completely missed. This violates a critical assumption of conventional capture-recapture models that every individual should have non-zero probability of detection, and leads to negatively biased abundance estimate. Accuracy and precision of the study was further affected due to very low captures and no recaptures. Barlow (2009) estimated the tiger density at 23.5 tigers $/ 100 \mathrm{~km}^{2}$ in Bangladesh Sundarban using the mean $95 \%$ fixed kernel female home range, assuming female territories to be exclusive and the sex ratio of Sundarban tigers to be similar to that observed in Chitwan, Nepal. He derived the population abundance of 335-1000 tigers in Bangladesh Sundarban by extrapolating the derived density across the total landmass of Bangladesh Sundarban (Barlow 2009). This number is questionable since it is based on untested assumptions of exclusive tiger territories and an application of an adult sex ratio from Chitwan, Nepal. Besides, the radiotelemetry data on which it is based comes from only two tigresses that were tracked for short durations. It is also believed that these tigresses occupied an unusually high prey density area that was not representative of the larger Sundarban landscape.

By repeating our camera trap exercise in the same area in subsequent years in a reasonably large and representative area of Sundarban, we demonstrate that tiger density is much lower than that reported by Barlow (2009) and higher than that reported by Karanth and Nichols (2000). With the use of (a) appropriate camera spacing which minimised the chances of missing resident tigers, (b) baits to lure and maximise tiger photo-captures, (c) selecting a suitable study area so as to ensure geographic closure and reduce the uncertainty associated with ETA, (d) explicitly modelling for differential capture and recapture probabilities due to baits as well as accounting for spatial heterogeneity in our analysis, and by (e) investigating if tiger density generated through camera trap based CMR is comparable with tiger abundance obtained from an independent assessment of prey based carrying capacity, we were able to achieve and demonstrate the reliability of our estimates.

The rewards for camera visitation (food and water) were small compared to the tiger's requirements and were replenished only after 2-3 days. Therefore, we believe that tiger movement, if at all altered, would be only at local scales. By modelling sigma, the movement parameter, and 
$\mathrm{g} 0$, the detection probability in SECR, for spatial heterogeneity and behaviour effects, we effectively accounted for the use of attractants. Furthermore, as demonstrated, SECR approach gave comparable results to the non-spatial estimate by traditional capture-mark-recapture analysis wherein GPS telemetry based home range radius of radiocollared tigers was used to buffer the camera bounding polygon further supporting our tiger density estimates. Additionally, there may be reservations about whether individuals residing outside the study area may get attracted to the camera traps by the usage of baits, thereby temporarily inflating the density. In our study, chances of attracting individuals outside the survey area were minimised by overseeing that the buffer between the outermost traps and the effective trapping area was larger than the distance over which traps can be detected (du Preez et al. 2014). We also delimited the study area by hard boundaries on three sides and included the adjacent sanctuary area of $326 \mathrm{~km}^{2}$ in the north as model inference space for SECR and ETA in non spatial models, and are therefore quite certain that use of attractants did not inflate local tiger density. Gerber et al. (2012) and du Preez et al. (2014) have further shown that in territorial animals like the Malagasy civet (Fossa fossana, Müller) and the leopard (Panthera pardus, Linnaeus), even if the baits were to work at great distances, the species' inherent territoriality would stop outsiders from frequenting the traps located in their territories. This same argument can be extended to the tigers as well, thereby forming a "biological" barrier (du Preez et al. 2014) against intruders from outside the trapped area.

Our study shows that camera trapping can be an effective tool for monitoring tigers in Sundarban with an appropriate design in combination with usage of attractants. The estimated densities using both the non-spatial, conventional home range radius to demarcate $\widehat{E T A}$ as well as the spatially explicit model are reliable and robust estimates as they are similar to the predicted carrying capacity considering chital as the only prey. The traditional CMR density estimates matched those obtained by SECR, this was likely because our study area was geographically closed due to water channels bordering it on most sides. Since our study area was representative of the mangrove forest of Sundarban, we believe that extrapolating this density to the entire tiger occupied mangrove forest (Jhala et al. 2011) of Sundarban could be justified so as to obtain a crude estimate of tiger numbers. Considering tigers to be occupying about $6000 \mathrm{~km}^{2}$ across Indian and Bangladesh Sundarban, the potential total number of tigers would be about 300 (SE 68). Given this conservative estimate of the population size and the contiguous nature and size of the Sundarban mangrove forests across India and Bangladesh, this tiger population would be one of the largest tiger populations in the world and may have a high probability of population persistence for the long-term. The biggest peril to this landscape, given the comparatively lower risk of habitat destruction by humans, is the rising sea level due to climate change which threatens to submerge $96 \%$ of the landmass and can have severe effect on tiger numbers in this isolated population (Loucks et al. 2010). Sundarban are the only mangrove forests in the world where the tiger lives, so if we are to save this uniquely adapted tiger and its landscape, conservation strategies must be executed at global (limiting carbon emissions), regional (cross-country cooperation between India and Bangladesh) and local scales (control of poaching) (Loucks et al. 2010).

Acknowledgments This study is an outcome of a collaborative project between Wildlife Institute of India and West Bengal Forest Department with the funding support from the National Tiger Conservation Authority. We thank the Director, Dean, Research Coordinator of Wildlife Institute of India and the Chief Wildlife Warden, Director- Sundarban Biosphere Reserve, Director- Sundarban Tiger Reserve for permissions and logistic support. We acknowledge the sincere efforts of Range Officers and Ground Staff for facilitating the field work. We thank Ranjit Mondal, Naresh Mondal, Goutam Patra and Srinivas Mondal for their sincere assistance in the field work. Lastly we thank Sutirtha Dutta for helping with data analysis and Swati Saini for help with the figures. The study was conceived by YVJ \& QQ; MR \& DN conducted the field work; MR, YVJ, QQ did the data analysis and wrote the paper; RG, KS, QQ, \& YVJ supervised the study and provided logistic support.

Open Access This article is distributed under the terms of the Creative Commons Attribution 4.0 International License (http://crea tivecommons.org/licenses/by/4.0/), which permits unrestricted use, distribution, and reproduction in any medium, provided you give appropriate credit to the original author(s) and the source, provide a link to the Creative Commons license, and indicate if changes were made.

\section{References}

Akaike H (1974) A new look at the statistical model identification. IEEE Trans Autom Control 19:716-723

Barlow AC (2009) The Sundarbans tiger adaptation, population status, and conflict management. $\mathrm{PhD}$ Thesis, University of Minnesota, Minneapolis

Barlow AC, Ahmad IU, Smith JL (2013) Profiling tigers (Panthera tigris) to formulate management responses to human-killing in the Bangladesh Sundarbans. Wildlife Biology in Practice 9:30-39

Blair HW (1990) Local government and rural development in the Bengal Sundarbans: an inquiry in managing common property resources. Agric Hum Values 7:40-51

Blasco F, Saenger P, Janodet E (1996) Mangroves as indicators of coastal change. Catena 27:167-178

Borchers DL, Efford M (2008) Spatially explicit maximum likelihood methods for capture-recapture studies. Biometrics 64:377-385

Burnham KP, Anderson DR (2002) Model selection and multimodel inference: a practical information-theoretic approach. SpringerVerlag New York Inc, New York

Chakrabarti K (1992) Man-eating tigers. Darbari Prokashan, Kolkata 
Chaudhuri AB, Choudhury A (1994) Mangroves of the Sundarbans. Volume 1: India. International Union for Conservation of Nature and Natural Resources (IUCN), Gland

Choudhury S (1970) Let us count our tigers. Cheetal 14:41-51

Choudhury S (1972) Tiger census in India. Cheetal 15:67-84

De R (1990) The Sundarbans. Oxford University Press, Kolkata

Dinerstein E, Wikramanayake E, Robinson J, Karanth KU, Rabinowitz A, Olson D, Mathew T, Hedao P, Connor M, Hemley G, Bolze D (1997) A framework for identifying high priority areas and actions for the conservation of tigers in the wild. World Wildlife Fund-US, Washington DC

du Preez BD, Loveridge AJ, Macdonald DW (2014) To bait or not to bait: a comparison of camera-trapping methods for estimating leopard (Panthera pardus) density. Biol Conserv 176:153-161

Efford M (2004) Density estimation in live-trapping studies. Oikos $106: 598-610$

Efford MG (2015) secr: Spatially explicit capture-recapture models. R package version 2.9.3. http://CRAN.R-project.org/package=secr. Accessed 28 June 2015

ESRI (2011) ArcGIS Desktop: Release 10. Environmental Systems Resource Institute, Redlands

Gerber BD, Karpanty SM, Kelly MJ (2012) Evaluating the potential biases in carnivore capture-recapture studies associated with the use of lure and varying density estimation techniques using photographic-sampling data of the Malagasy civet. Popul Ecol 54:43-54

Hayward MW, O'Brien J, Kerley GI (2007) Carrying capacity of large African predators: predictions and tests. Biol Conserv 139:219-229

Islam MS, Wahab MA (2005) A review on the present status and management of mangrove wetland habitat resources in Bangladesh with emphasis on mangrove fisheries and aquaculture. In: Segers H, Martens K (eds) Aquatic biodiversity II. Springer, Netherlands, pp 165-190

Jhala YV, Qureshi Q, Gopal R, Sinha PR (eds) (2011) Status of tigers, co-predators and prey in India, 2010. National tiger conservation authority and wildlife institute of india. Dehradun. TR 2011(003):1-302. http://www.butchlama.com/Wild_India/ Tiger_Census_files/staus_tiger_2010\%20WII.pdf

Kanjilal B, Mazumdar PG, Mukherjee M, Mondal S, Barman D, Singh S, Mandal A (2010) Health care in the Sundarbans (India): challenges and plan for a better future. Institute of Health Management Research, Jaipur and Kolkata

Karanth KU, Nichols JD (1998) Estimation of tiger densities in India using photographic captures and recaptures. Ecology 79:2852-2862

Karanth KU, Nichols JD (2000) Ecological status and conservation of tigers in India. Final Technical Report (February 1995 to January 2000). Centre for Wildlife Studies, Bangalore

Karanth KU, Nichols JD, Seidenstricker J, Dinerstein E, Smith JLD, McDougal C, Johnsingh A, Chundawat RS, Thapar V (2003) Science deficiency in conservation practice: the monitoring of tiger populations in India. Anim Conserv 6:141-146

Khan MH (2004) Ecology and conservation of the Bengal tiger in the Sundarbans mangrove forest of Bangladesh. PhD Thesis, University of Cambridge, Cambridge
Kvale EP (2006) The origin of neap-spring tidal cycles. Mar Geol 235:5-18

Lebreton JD, Burnham KP, Clobert J, Anderson DR (1992) Modeling survival and testing biological hypotheses using marked animals: a unified approach with case studies. Ecol Monogr 62:67-118

Loucks C, Barber-Meyer S, Hossain MAA, Barlow A, Chowdhury RM (2010) Sea level rise and tigers: predicted impacts to Bangladesh's Sundarbans mangroves. Clim Change 98:291-298

Mukherjee S (2005) Ecological investigations on mangroves of the Sundarbans Tiger Reserve in West Bengal (India) with special reference to effective conservation through management practice. PhD Thesis, University of Kalyani, Kalyani

Neumann-Denzau G, Denzau H (2010) Examining certain aspects of human-tiger conflict in the Sundarbans forest, Bangladesh. Tigerpapers 37:1-11

Otis DL, Burnham KP, White GC, Anderson DR (1978) Statistical inference from capture data on closed animal populations. Wildl Monogr 62:3-135

Qureshi Q, Gopal R, Shirish K, Basu S, Mitra A, Jhala YV (2006) Evaluating tiger habitat at the Tehsil level. Project tiger directorate and Wildlife Institute of India, Dehra Dun

R Core Team (2015) R: A language and environment for statistical computing. R Foundation for Statistical Computing, Vienna, Austria. http://www.R-project.org/ Accessed 28 June 2015

Rahman LM (2000) The Sundarbans: a unique wilderness of the world. Proceedings - Rocky Mountain Research Station, USDA Forest Service 2000 No. RMRS-P-15 2:143-148

Sanderson E, Forrest J, Loucks C, Ginsberg J, Dinerstein E, Seidensticker J, Leimgruber P, Songer M, Heydlauff A, O’Brien T, Bryja G, Klenzendorf S, Wikramayake E (2006) Setting priorities for the conservation and recovery of wild tigers: 2005-2015. The Technical Assessment, WCS, New YorkWashington, DC

Seber GAF (1973) The estimation of animal abundance and related parameters. Griffin, London

Singh SK, Mishra S, Aspi J, Kvist L, Nigam P, Pandey P, Sharma R, Goyal SP (2015) Tigers of Sundarbans in India: is the population a separate conservation unit? PLoS One. doi:10.1371/journal. pone.0118846

Thomas L, Laake JL, Rexstad E, Strindberg S, Marques FFC, Buckland ST, Borchers DL, Anderson DR, Burnham KP, Burt ML, Hedley SL, Pollard JH, Bishop JRB, Marques TA (2009) Distance 6.0. Release 2. Research Unit for Wildlife Population Assessment, University of St. Andrews, Fife

Thomas L, Buckland ST, Rexstad EA, Laake JL, Strindberg S, Hedley SL, Bishop JR, Marques TA, Burnham KP (2010) Distance software: design and analysis of distance sampling surveys for estimating population size. J Appl Ecol 47:5-14

White GC, Burnham KP (1999) Program MARK: survival estimation from populations of marked animals. Bird Study 46:120-138

Williams BK, Nichols JD, Conroy MJ (2002) Analysis and management of animal populations. Academic Press, San Diego

Yoccoz NG, Nichols JD, Boulinier T (2001) Monitoring of biological diversity in space and time. Trends Ecol Evol 16:446-453 